\title{
Neutralizing pattern deviations in ocular motility
}

\author{
MARTIN J. URIST \\ From the Motility Clinic of the Illinois Eye and Ear Infirmary, University of Illinois College of \\ Medicine, Chicago, Illinois
}

Patients are frequently seen who show heterotropias on gaze in opposite directions, such as an esotropia on looking right and an exotropia on looking left, or a right hypertropia on looking up and a left hypertropia on looking down. These antipodal deviations may occur naturally as a congenital derangement, or may develop as a result of surgery or trauma (Urist, I964). Fortunately, in most cases, they balance one another so that the eyes become straight, that is, vertically and horizontally aligned, in some neutral position of gaze. Because of this balancing tendency and the ability to develop straight eyes, I call them "neutralizing pattern deviations".

More than half of about 4,00o cases of strabismus examined over the past 20 years have had at least one type of neutralizing pattern deviation. To my knowledge there exists no comprehensive report on all types of neutralizing deviations, no classification, and no nomenclature for discussing them. In this paper I shall classify, discuss, and illustrate the types of neutralizing deviations I have seen.

Somewhere between the opposite directions of gaze in which opposite deviations occur is the "neutral position" where binocular vision is achieved. It may be a large area or a point, the neutral point, depending on the patient's amplitude of fusion.

The neutral position is most commonly located in the primary position, in which the eyes and the head are directed straight ahead. In some cases it is located in an eccentric position and results in a dissociation between the position of the eyes and that of the head. In these cases the head is turned, the direction depending on the position of the neutral point when the eyes are directed straight ahead. It may be a head turn to the right or left, a head tilt to the right or left shoulder, a head bend up or down, or any combination of these.

Cogan (1967) described the neutral point in opposite rapid component nystagmus on gaze in opposite directions as follows:

The typical motor defect type of nystagmus shows a jerky nystagmus on gaze to either side with the fast component in the direction of gaze. At some neutral point between, the eyes are relatively stationary. The neutral point may be where the eyes are directed straight ahead or eccentrically. The vision is usually normal at the neutral point and the patients with this type of nystagmus habitually turn their heads so that the eyes are maintained in a position of relative rest.

Antipodal heterotropias of various degrees may occur in every position of gaze, often at the same time in the same patient. The diversity of these deviations sometimes requires study to determine whether the eyes can be straight in some position. The following classification of these complex neutralizing pattern deviations will enable the oculist to recognize them more readily. 


\section{Classification}

\section{Neutralizing horizontal deviations on:}

A. VERTIGAL GAZE

(I) Neutralizing $V$ pattern - exotropia up, esotropia down, with head bend up or down if the neutral position is eccentric (See Cases I, 3, and 7).

(2) Neutralizing A pattern-esotropia up, exotropia down, with head bend up or down if the neutral position is eccentric (See Case 2).

B. LAteral GAZE-esotropia on looking right, exotropia on looking left, or vice versa, with a head turn to the right or left if the neutral position is eccentric (See Cases 3 and 7).

C. DISTANGE AND NEAR-exotropia for distance, esotropia for near, or vice versa (See Cases I, 3 , and 7).

\section{Neutralizing vertical deviations on:}

A. VERTICAL GAZE--left hypertropia on looking up, right hypertropia on looking down, or vice versa, with a head tilt, turn, bend, or any combination thereof, if the neutral position is eccentric (See Cases 4 and 6).

B. LATERAL GAZE

(I) Bilateral elevation in adduction - right hypertropia on looking left, left hypertropia on looking right (See Cases I and 7).

(2) Bilateral depression in adduction-right hypertropia on looking right, left hypertropia on looking left, with a single or combined head deviation if the neutral position is eccentric (See Case 2).

c. овLIQUE GAZE-elevation and depression of the same eye in adduction on looking in the same direction obliquely up and down (See Cases 4,5 , and 6).

D. HEAD TILT-right hypertropia on tilt to the right, left hypertropia on tilt to the left, or vice $\frac{0}{O}$ versa. When the opposite hypertropias are of equal magnitude, the neutral position is usually in primary position. When one hypertropia is greater, the neutral position may be attained by a head tilt to the side of the smaller deviation (See Case 7).

\section{Case reports}

Case I, an II-year-old girl (Fig. I) with an intermittent right esotropia since 3 years of agc, exhibited the following three neutralizing pattern deviations:

Exotropia for distance, esotropia for near;

Exotropia on looking up, esotropia on looking down;

Right hypertropia on looking left, left hypertropia on looking right.

The neutral position was looking straight ahead.

Case 2, an 11-year-old girl (Fig. 2), who was moderately hypermetropic, with a congenital inter-? mittent accommodative right esotropia, exhibited two neutralizing pattern deviations: a neutralizing A pattern, and bilateral depression in adduction. Wearing $+3.50 \mathrm{D}$ sph. lenses, her neutral position was looking straight ahead where she achieved stereopsis. 


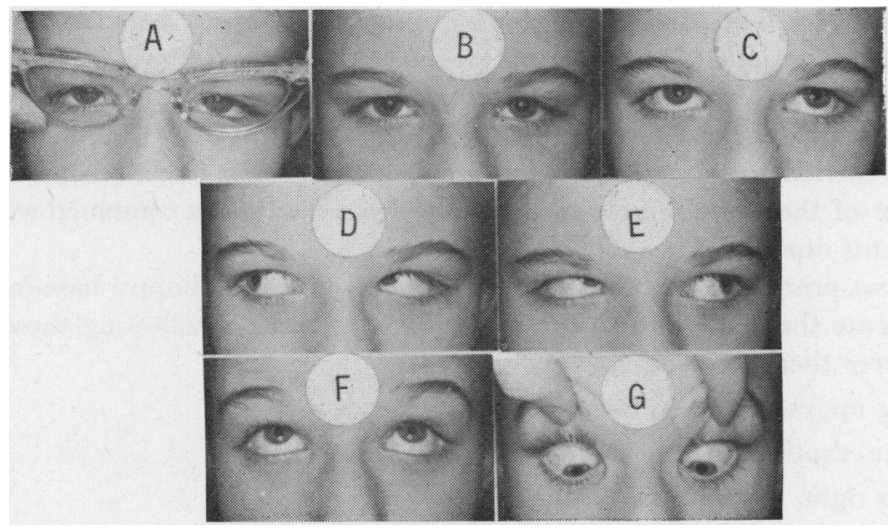

FIG. I Case I

(a) Eyes straight in primary position with glasses.

(b) $5^{\circ}$ esotropia for near without glasses.

(c) $10^{\circ}$ exotropia for distance without glasses.
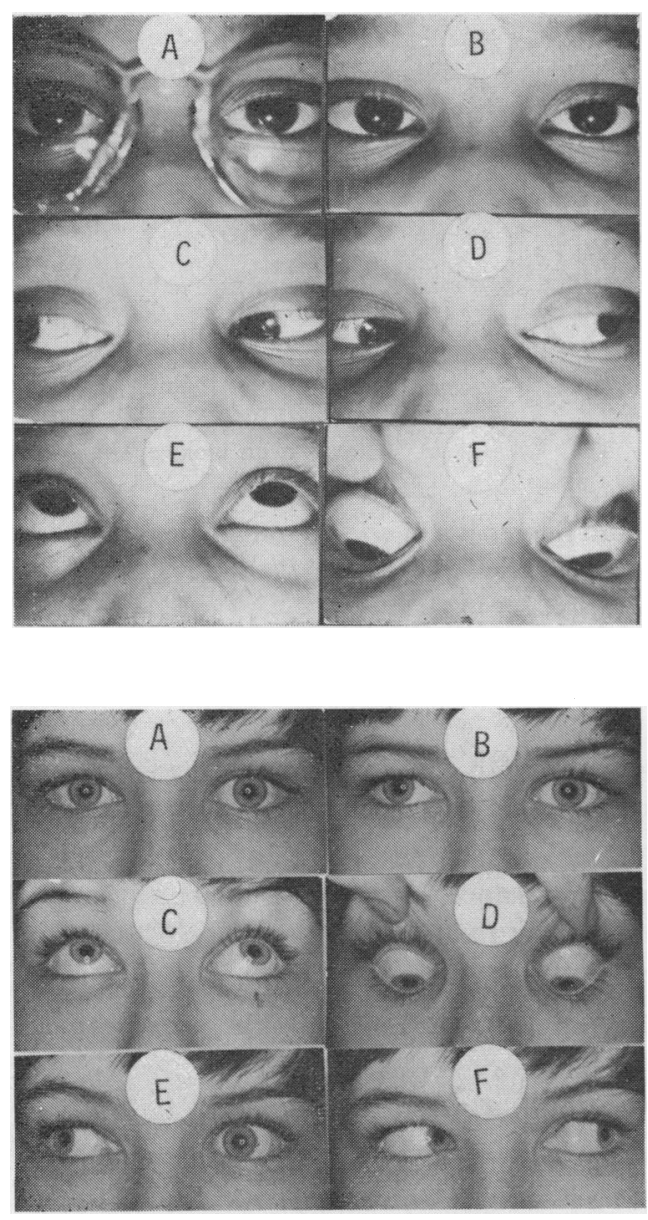

$(d, e)$ Bilateral elevation in adduction.

$(f) 10^{\circ}$ exotropia on looking up.

(g) $10^{\circ}$ esotropia on looking down.

\section{FIG. 2 Case 2}

(a) Eyes straight with glasses in primary position.

(b) $15^{\circ}$ right esotropia for near without glasses in primary position.

$(c, d)$ Bilateral depression in adduction.

(e) $15^{\circ}$ right esotropia on looking up.

(f) $15^{\circ}$ right exotropia on looking down.
FIG. 3 Case 3

(a) Slight right eso:ropia for near.

(b) $15^{\circ}$ of right exo' ropia for distance.

(c) $15^{\circ}$ left exotropiz on looking up.

(d) Eyes straight on looking down.

(e) Exotropia on looking right.

(f) Slight esotropia cn looking left. 
Case 3, a 13-year-old boy (Fig. 3), after surgery for an esotropia which began at age 7 , developed a horizontal neutralizing pattern of esotropia on looking right and exotropia on looking left. His neutral position was about $10^{\circ}$ left of centre. Consequently he turned his head to the right. When his head was held straight he had an exotropia with crossed diplopia. The following surgical procedures had been carried out: at age 7, a $5 \mathrm{~mm}$. recession of the left medial rectus muscle, and at age $\mathrm{I}$, a re-recession of the same muscle to $\mathrm{I}$. $5 \mathrm{~mm}$. from the limbus combined with a resection of the left lateral rectus muscle.

A 5 dioptre base-out prism was placed before the right eye and a 5 dioprre base-in prism before the left eye to eliminate the head turn to the right (Fig. 4), and the following three neutralizing pattern deviations were then observed:

Exotropia on looking up, esotropia on looking down;

Esotropia for distance, exotropia for near;

Exotropia on looking right, esotropia on looking left.

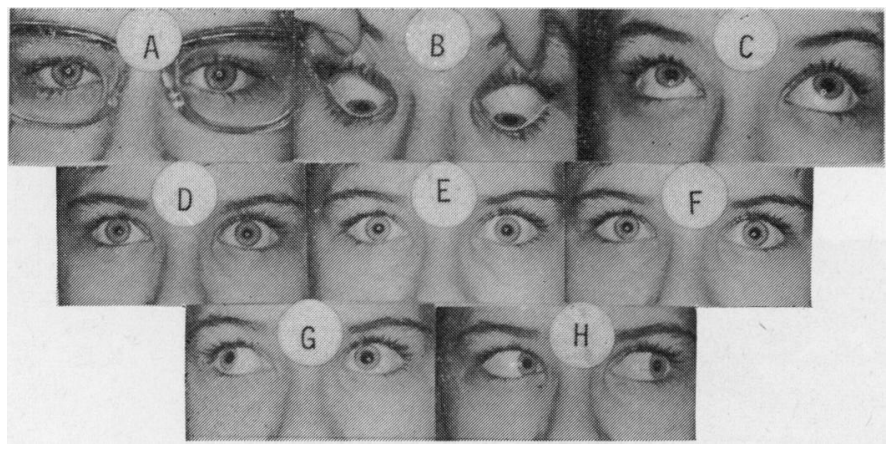

FIG. 4 Case 3 after application of prisms

(a) Eyes and head straight in primary position when wearing prisms.

(b) Esotropia on looking down.

(c) Exotropia on looking up.

(d) Right exotropia for distance. (e) Eyes straight.

(f) Right esotropia for near.

(g) Exotropia on looking right with underaction of the left medial rectus muscle.

(h) Esotropia on looking left.

Cases 4, 5, and 6 all showed elevation and depression of one eye on looking obliquely up and down (Fig. 5, opposite). Their neutral positions are shown in $5(a),(f)$, and $(j)$ respectively.

Case 4 was examined one year after an untreated blowout fracture of the right orbit.

Case 5 showed Duane's retraction syndrome of the left eye.

Case 6 had residual long-standing right IIIrd nerve paralysis.

Case 7, a ro-year-old girl (Fig. 6, opposite) with congenital intermittent esotropia and head tilt to the left, exhibited three types of horizontal and two types of vertical neutralizing pattern deviations:

HORIZONTAL DEVIATIONS Exotropia for distance, esotropia for near; exotropia on looking up, esotropia on looking down; exotropia on looking right, esotropia on looking left.

VERTICAL DEViations Right hypertropia on looking left, left hypertropia on looking right; right hypertropia on head tilt to the left, left hypertropia on head tilt to the right.

Prism cover measurements with the head tilted to the right:

$\mathrm{ET}{ }_{12} \Delta, \mathrm{LH}_{10}{ }^{\triangle}$; and with the head tilted to the left: $\mathrm{ET}_{12} \triangle, \mathrm{RH}_{4} \Delta$.

With the head tilted a little to the left the patient maintained a neutral position on looking straight ahead. 


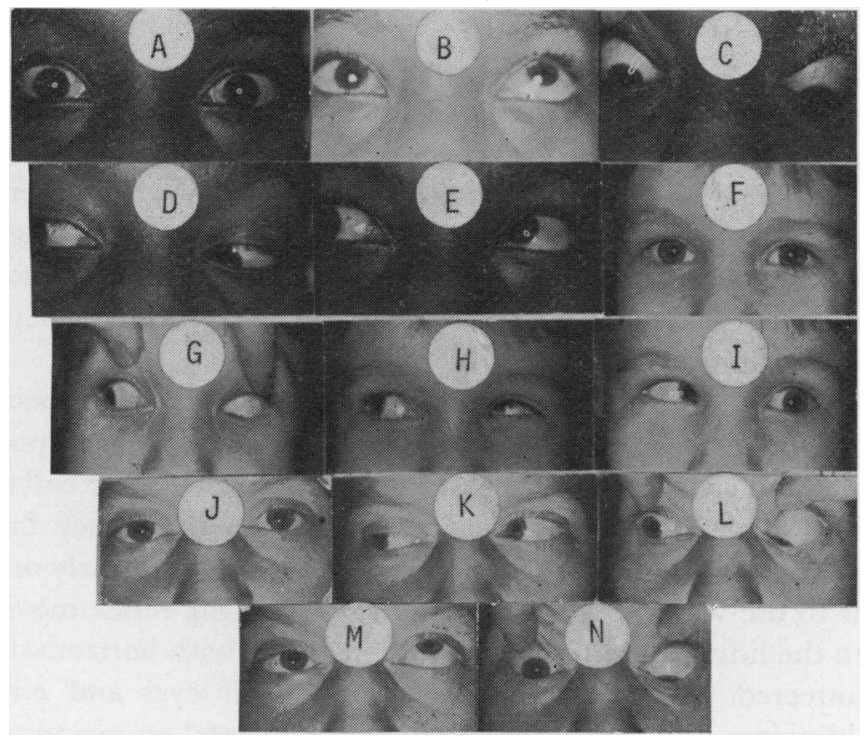

FIG. 5 Cases 4 to 6

\section{Case 4}

(a) Neutral position on looking straight ahead with head slightly tilted to the right shoulder

(b) Left hypertropia on looking up with diplopia.

(c) Right hypertropia on looking down with diplopia.

(d) Depression of left eye in adduction.

(e) Elevation of left eye in adduction.

Case 6

(j) Neutral position on looking straight ahead.

(k) Elevation of left eye in adduction.

(l) Depression of left eye in adduction.

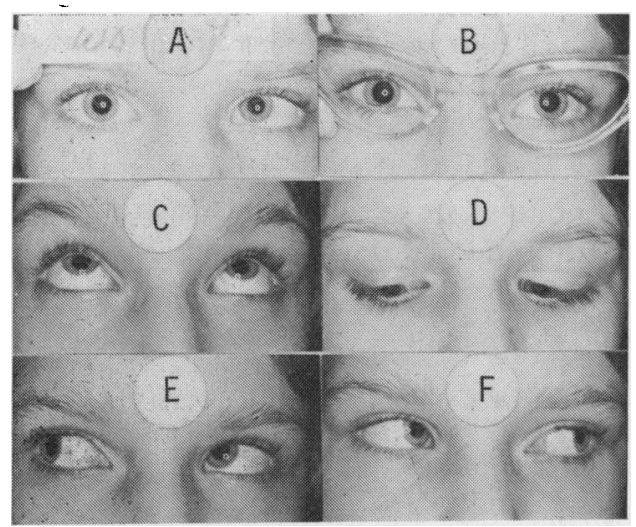

Case 5

$(f)$ Neutral position on looking straight ahead with slight head turn to the left.

(g) Depression of left eye in adduction.

(h) Elevation of left eye in adduction with narrowing of the left palpebral fissure.

(i) Limitation of left eye in adduction with widening of the left palpebral fissure.

(m) Left hypertropia on looking up.

(n) Right hypertropia on looking down.

FIG. 6 Case 7

(a) $10^{\circ}$ left esotropia and $5^{\circ}$ left hypertropia for near.

(b) $5^{\circ}$ left exotropia for distance with glasses.

(c) $5^{\circ}$ exotropia on looking up.

(d) $10^{\circ}$ left esotropia on looking down.

$(e, f)$ Bilateral elevation in adduction, greater in the left eye; exotropia on looking right, slight esotropia on looking left. 


\section{Comment}

In many cases the eyes may be only intermittently straight in the neutral position. At the $\frac{\text { o }}{.}$ time of examination they are often dissociated. Then the various combinations of opposite $\vec{F}$ kinds of vertical and horizontal tropia deviations can become very confusing. Keeping in mind the above classification and looking for some position where there may be a neutral point and where the patient may have fusion helps to clarify the diagnosis.

Fusion was elicited in six of the seven patients described above. It is the most important $\stackrel{\mathbb{\Omega}}{\Omega}$ factor in the presence of heterotropias for developing and maintaining a neutral position with or without turning the head.

Where large heterotropias occur it is interesting to consider how alignment of the eyes is adjusted so that fusion can become operative to develop a neutral position. One $\vec{\omega}$ common way is by trial and error. Patients with diplopia, or what some call a visual blur, $\frac{0}{0}$. adopt various positions of gaze to try to clear their vision. Once they find a neutral in position they tend to maintain it or to assume it when desiring to see clearly or binocularly.

Another method is to use what appears to be an eye-centering reflex movement which $\vec{\bullet}$ comes into play when the lids are tightly shut. Patients with both horizontal and vertical deviations had volunteered that they could straighten their eyes and eliminate their $\frac{\text { ? }}{\square}$ diplopia or blur by blinking, and this observation was confirmed on examination. Con- $\vec{z}$ sequently I began the practice, in examining patients with derangements of ocular motility, of testing the effect of closing the eyes. I found that large deviations, both vertical and $\stackrel{S}{5}$ horizontal, could be made to disappear by this manoeuvre. Careful observation of $\vec{\theta}$ deviating eyes after thev had been kept tightly shut revealed that in most cases they. would appear momentarily straight before returning to the original deviation; in other cases they would remain straight until dissociated.

Bender and Shanzer ( 1964 ) considered that centering movements of the eyes in monkeys were a distinct form of eye movement. They found that, upon electric stimulation of $\frac{O}{D}$ certain areas of monkeys' brains, regardless of the position of the eyes before stimulation, each eye would move toward the centre of the orbit.

One may speculate that these centering movernents are also important in human physiology, and it is certain that they require further study.

\section{Summary}

Neutralizing pattern deviations are antipodal deviations (such as exotropia on looking 3 left and esotropia on looking right, or left hypertropia on looking up and right hypertropia $\delta$ on looking down) which can balance each other so that the eyes become vertically and $₹$ horizontally aligned in some neutral position. The neutral position can be a point or a $\frac{\text { o }}{2}$ large area depending on the amplitude of fusion. It is most often found in the primary $\frac{D}{0}$ position, and when it is in some eccentric position of gaze it is usually accompanied by a turn or tilt of the head.

Neutralizing pattern deviations may be classified as horizontal or vertical and by the $\mathbb{N}$ direction of gaze, vertical, horizontal, oblique, or torsional, in which they occur.

Two methods by which patients with antipodal deviations achieved ocular alignments are described.

\section{References}

BENDER, M. B., and Shanzer, s. (1964) In "The Oculomotor System", ed. M. B. Bender, p. 94.

Harper and Row, New York

cogan, v. G. (1967). Canad. 7. Ophthal., 2, 4

crist, м. J. (1964) Amer. J. Ophthal., 57, 7 I9 